\title{
Change Management in MNC: How Global Convergence Intertwines with National Diversities
}

\begin{abstract}
The paper presents three case studies of three of the four global players in the lifts- and escalator industry (controlling $3 / 4$ of the respective world market). It is based on chiefly qualitative data from the headquarter level (based in the US, Finland and Germany) and comparative data from their British and German subsidiaries. The object of the research are change management processes in the work systems on the subsidiary level. The central research question of the study is to analyze how these processes are shaped by globalization on the one hand and national institutional contexts on the other hand.

In doing so, the authors position their research between the two dominant families of approaches in international business research, recently characterized by Child as "lowcontext" and "high-context" approaches. Low-context approaches see forces of economic universalism, technology and psychological universalism as inevitably working towards globally increasingly convergent and uniform organizational structures in MNCs. Highcontext approaches see cultural and institutional factors as the dominant drivers which lead to organizations that are deeply adapted to national and regional specifics.

The study is process- (rather structure-) oriented and shows how global and national effects shape the design of the work systems at the subsidiary level and reveals that there is no one way of globalizing in MNCs. The analysis in this paper focuses on the cross-national comparison of the subsidiaries, but at the same time highlights the relevancy of the societal institutions of MNC's home countries as well.
\end{abstract}

\section{Keywords}

high-/low-context approaches; Anglo-German comparison; national institutions 


\section{Change Management in MNC: \\ How Global Convergence Intertwines with National Diversities}

\section{Introduction}

More than three decades of research in international business have brought about an immensely great and diverse body of literature on transnational organizations. Not only the sheer number of studies but also the diversity of approaches, methods and theories used lead to a situation where the field looks rather fragmented, providing often irreconcilable views on the issues discussed (Boddewyn \& Iyer, 1999; Buckley \& Chapman, 1999).

This also seems to be the case in the present debate on the impact of globalization on the multinational corporation (MNC). On the one hand, it is argued that MNCs can be regarded as “stateless” (Parker, 1998), “transnational” (Bartlett \& Ghoshal, 1989) or "highly

globalized” (Lane, 2000) organizations that are to an increasing lesser degree shaped by their respective national environment. This is one extreme position, recently under attack from different angles. On the other hand, the relevancy of national and/or regional environments for the activities of MNCs are regarded by others as key factors, amounting to the very denial of globalization (Rugman, 2000) on the other extreme of the spectrum.

In this paper we argue that both research streams have a point. But we also want to go a step further: while we admit that there is a strong force towards global conformity in MNCs we acknowledge at the same time, that national environments still have a dominant influence on MNCs, both at headquarter (HQ) and subsidiary levels. The focus of this research project is how precisely global forces and national influences come together in shaping the management processes within MNCs. In addressing this problem the paper takes a cross-national perspective and focuses mainly on change management processes (CMPs) in British and German subsidiaries of three leading multinationals in the same industrial sector.

\section{Theoretical Background}

At the 2000 Conference of the Academy of Management, a special workshop was dedicated to the state of the art in international business research (Child, 2000, as well as the discussant's papers in the same volume). As the presented analysis is quite helpful in 
positioning our research, we will draw on the framework proposed by Child in relating our work to the literature thus far (see Figure 1).

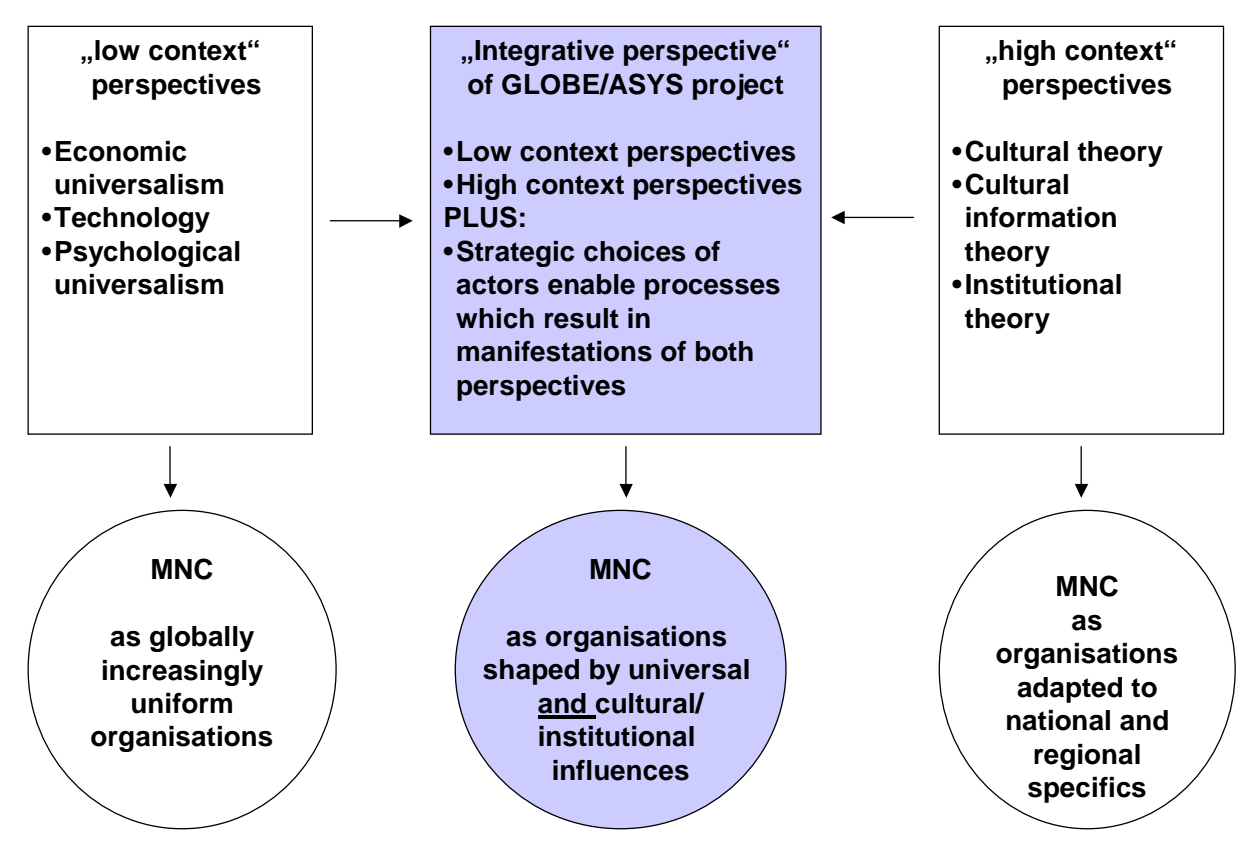

Figure 1: Theoretical Basis: Bridging the gap in international management research

Child characterizes the various approaches according to the criterion of "their sensitivity to nations or regions as analytically significant contexts” (Child, 2000: 30). Consequently one can identify research that pays high attention to national contexts ("high context” perspectives) and those that refer to universal rationales and are insensitive to specific national contexts ("low context” perspectives). Low context perspectives see corporations structured by their environment which in most cases consists of markets. Along these lines, beginning with Chandler, various authors such as Bartlett \& Ghoshal (1989) and others (see Rank, 1999 as an overview) have conceptualized the "multiunit business enterprise” as the dominating, transnationally homogeneous pattern of organizing. Recently, Whittington and Mayer have argued that, even in Europe, despite a variety of national differences, this American Chandlerian multiunit business enterprise model is increasingly the standard organizational form for corporations as well (Whittington \& Mayer, 2000). Next to these economic factors, low context perspectives stress the role of technology, especially information technology, in leading to global organizations which become increasingly homogeneous. Finally, Child identifies the common assumption in low context theories that 
all human beings are common in their needs and motivational structures as a third powerful pillar of these low context approaches. "High context” perspectives, on the other hand, see organizations as institutionally deeply enrooted and socially embedded into their respective national contexts. National cultures and national institutions significantly influence organization and MNCs that work in different national contexts and the massive opening up of the Eastern European and Asian economies have given considerable significance to these research perspectives.

The interesting point - from the perspective of our research - about Child's analysis is, however, that he identifies the need to integrate both perspectives when doing research in transnational organization. Globalization, on the one hand, strengthens the argument of "low-context" perspectives as it leads to an increasing world-wide convergence and standardization of market conditions, technologies, HRM practices and decision making processes in corporations. On the other hand, globalization also makes differences in national cultures and institutions even more visible as it brings these often diverse contexts closer together. So he concludes:

"The question therefore arises as to how and where, within an overall trend toward globalization, national cultures and institutions will continue to shape organizational forms and behavior" (Child, 2000: 54-55)

The trend towards convergence and world-wide standardization of organizational structures and practices are clearly visible in the companies in our sample. Therefore we take those "low context" perspective as a starting point of our research. This stream of research on the subsidiaries of MNCs is heavily influenced by ideas which see transnationals as differentiated networks in the sense of Bartlett/Ghoshal as well as Nohria/Ghoshal (Bartlett et al., 1989; Nohria \& Ghoshal, 1997). More current work on the role of subsidiary initiatives and change management in subsidiaries in order to develop new markets and product innovation indicates the emergence of a growing independency of subsidiaries from headquarters’ decision making (Birkinshaw \& Fry, 1998; Birkinshaw \& Hood, 2001). However, the research of our German colleagues indicates that control and coordination by the headquarters takes quite different forms in each MNCs of our sample (BeckerRitterspach, Lange, \& Lohr, 2001): the headquarters are still playing a vital role in decisions about change management measures and are not just devolving their power resources to regional centers within a then differentiated multinational network as indicated by research on the "transnational solution”. To sum it up, we think that low-context approaches focus too 
much on particular structural configurations of MNCs rather than processes, key actors and their strategic choices (Geppert, Matten, \& Williams, 2001a).

Therefore it is inevitable, given our interest in not only global rationalities but also in national contexts, that we build on other streams of research on MNCs than just the low context perspectives. A first stream of research in the "high-context" perspectives focuses on the identification of the effect of the MNC's country of origin on its operations in different national environments (e.g.Edwards \& Ferner, 2000). This research perspective sheds light on the fact, that MNCs' strategies are strongly influenced by the cultural and institutional context of their home country, as evident, for instance, in Japanese MNCs that have operations in Europe (Morgan, Kelly, Sharpe, \& Whitley, 2001). In our research we specifically focus on the institutional environment such as the legal framework, ownership structures, educational system, industrial relations etc. of the country where the MNC HQ is based and investigate how they influence the strategy of the whole multinational group. The project intends to identify the conditions and processes that lead to a specific "country of origin effect”.

In analyzing these country of origin effects we extensively draw on a second stream of research, which is the national business systems approach, mostly linked to names such as Whitley (Whitley, 1992), Lane (Lane, 1992) or Sorge (Sorge, 1995). This approach does not only help to explain the influence of the national business system on the whole multinational group, such as Morgan et al.'s work in comparing British, German and Japanese MNCs (Morgan et al., 2001), but it also helps to explain influences of the respective national business system on the national subsidiaries of the MNC which is the perspective of this study. Furthermore, this position may be helpful in explaining differences in how multinational groups share work and competencies internally as these were quite significant in our research.

Thirdly, there is a stream of research which one might call "global organizational effect approach” (e.g. Lane, 2000; Mueller, 1994; Parker, 1998). This perspective acknowledges the limitations of national societal effect approaches in explaining and integrating the effect of globalization on the harmonization and standardization of certain elements of the national business context. Not only does globalization affect the national business environment, but it also shapes the processes within the multinational group. Thus, approaches such as Mueller's stress that the organizational development of global manufacturing strategies and diffusion of technologies, knowledge or best practices, such as benchmarking, will undermine national institutional societal effects (Mueller, 1994: 419- 
421). Moreover, Lane criticises the fact that researchers of national societal effects ignore the impact of global MNC specific factors "on domestic institutional structures and the danger that it might blow apart the whole societal syndrome and thus undermine the social coherence of current German models of production organization and industrial relations” (Lane, 2000: 207).

\section{Change management process of the MNCs: Intertwining of globalization and national effects in the designing of subsidiary work systems}

Following Child (2000), who sees research oriented toward change and development consistent with his “evolutionary framework for cross-national organizational analysis”, our research into change management processes in MNCs is concerned with the potential dynamics over time of high context and low context factor influence and how this relates to the design of work systems at the level of national subsidiaries. However, we distinguish between global and national contextual forces which have both low context (e. g. economic and technological) and those with high context (institutional and cultural) dimensions. Consequently, our hypothesis is that change management processes at the local subsidiary level are guided by both low context factors including global economic or technological forces such as the introduction of global products, production, budgeting or benchmarking systems, and also by more national specific design of work systems in terms of product development, market strategy, work organization and skill development.

For the analysis of global and national effects in the following study we will refer to them as two specific effects. By the "globalization effect” (GE) we describe all influences on the organization which derive from the ongoing globalization process. We understand globalization as the process of denationalisation of social interaction as a result of ongoing political deregulation, accelerated economic (neo-) liberalization of trade and foreign direct investment, rapid technological advances in transportation and communication systems and, on the social field, increasing convergence of global cultural systems and educational models (Held \& McGrew, 2000; McGrew, 1997; Zürn, 1997). As such, globalization affects especially those factors which are the focus of research in the "low-context" perspective (markets and products), and leads to a global convergence in economic policies, markets and the cultural and institutional framework of business. The globalization effect, by some also called "transnational effect” (Child \& Yan, 2001), works towards (as Ohmae indeed calls it as well) the "denationalization” of companies and products (Ohmae, 1990). Likewise, Bartlett and Ghoshal (1989, 16-17) stress that the evolution of their transnational solution 
requires transitional structures to enable worldwide learning and, through the development of a global culture, a new management mentality. Globalisation in the MNC leads to a worldwide standardization of management systems, production processes, R\&D processes and marketing strategies.

The contrast to the globalization effect then is the "national effect" (NE) by which we understand the impact of national culture and institutions on the corporation. The NE thus reflects heavily the influence of "high-context" approaches. This effect includes the influence of national institutions such as educational and financial systems or governmental institutions (Lane, 1992; Whitley, 1992) but we will look especially at nation-specific differences in work systems, ranging from mass production at one extreme to diversified quality production at the other (Sorge \& Streeck, 1988). Furthermore, our research suggested strong national peculiarities in the relevant market characteristics: national differences manifest themselves in whether the competition in a market is more price oriented or quality oriented.

Starting from the assumption that low context and even high context factors do not directly determine decision making processes of local managers, we assume that they have some autonomy in terms of strategic choice and power resources to design their work systems at the national subsidiary level (Geppert, Williams, \& Matten, 2001b). We tried to show in this earlier work that the extent of plant autonomy of national subsidiaries is directly linked to their national business system. The national institutional context gives German subsidiaries superior power resources and strategic choices compared to their British counterparts in the same multinational group and across all of the three analyzed MNCs. Based on the empirical findings of this study, this paper compares similarities and differences in work system design in six German and British subsidiaries in relation to the change management strategies implemented within the MNC.

For our comparative analysis of work systems design in British and German subsidiaries of three MNCs we draw on the conceptualization of "work systems" outlined by Sorge (Sorge, 1993) and Whitley (Whitley, 1999). Work systems are the central object of our study where the impact of GE and NE are manifested. They can be conceptualized in more general terms as distinctive patterns of interconnected characteristics of (a) task organization and control, (b) workplace relations between social groups, and (c) employment practices and policies (Whitley, 1999:90). More specifically, work systems have their concrete manifestation in (1) the organizational structure (which can be differentiated by function, market, geographical region or products), (2) the organizational processes which 
contain communication flow, coordination control mechanisms, political and power relations, (3) the technologies used and (4) the employment practices and policies of the MNC (Sorge, 1993: 4-5). In the empirical discussion of our company cases we relate our analysis of change management processes mainly to the latter four components of work systems in German and British subsidiaries. Despite our analytical focus on the AngloGerman comparison, we are aware that change management processes in the subsidiary's work systems design cannot be described without reference to their economic and social relations within the MNC as a whole. Thus, the function, design and performance of a particular national subsidiary influence its power potential and scope for strategic choices within the multinational group (Geppert et al., 2001b). Therefore, far from neglecting the MNC level of analysis, we see the strength of our perspective in the fact that we can better understand how global forces and national influences come together and shape the design of change management processes at the national plant level.

\section{Research Design and Methodology}

Figure 2 shows how we assume these two major effects outlined above work in the context of the MNC. If we look at the upper part of Figure 2 we have both GE and NE working in the home country of the MNC. GE on the one hand affects the corporation directly by shaping the international business environment of the MNC. On the other hand, GE also affects strongly the national business environment: depending on the conditions of the national business system, some countries are quite significantly exposed to pressures toward international convergence. So, for instance, the Finnish capital market has been subject to rapid and powerful influence from international investors during recent years and has lost much of its traditional national characteristics (Tainio, 2001), which manifests a significant influence of the GE on the NE in this national context. Furthermore, there is a dialectic effect to globalization in that it stresses the awareness of cultural differences and thus the need to care for nationally specific needs (Child, 2000: 51; see also Sorge, 2000) - a phenomenon that becomes particularly important at the subsidiary level of the MNC.

CMPs are determined by the general strategies of the MNC, mainly at HQ level. Subsequently, these changes are implemented within the subsidiaries, in our case the subsidiaries in Germany and Britain. These change processes become manifest in concrete changes in the work systems of the subsidiaries. In our research we identify the various CMPs taking place and their specific effects on the work systems. However, these CMPs are influenced and shaped by both GE and NE in the same manner as GE and NE influence the 
HQ of the company. The difference is that the nature of the NE (and also the strength of the GE) in our comparative research in Britain and German are significantly different. This enables us to draw conclusions by comparing nationally differing results of the same groupwide change processes within the multinational group.

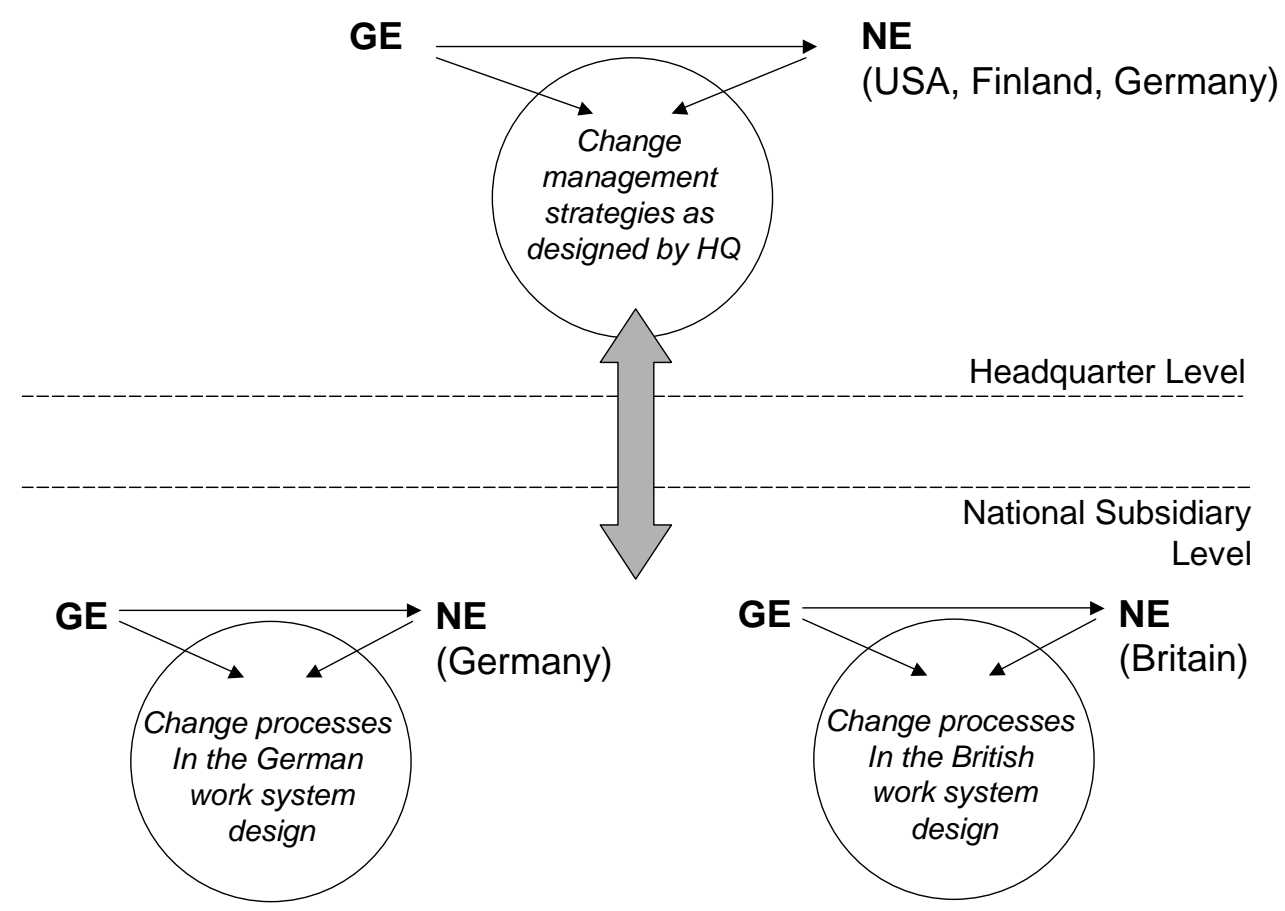

Figure 2: Research Design

The idea and design of the research project to analyse change management processes in MNC was jointly developed by the GLOBE research group in Swansea and researchers from the a group at Humboldt University in Berlin (ASYS group). To analyse these issues we have used the following methodology. We selected three of the four major global players of a relatively small business sector, Lifts \& Escalators. All have headquarters in different host countries; Amy in the USA, Jukka in Finland and Karl-Heinz in Germany. All three companies have national subsidiaries in Germany and in the UK. Worldwide, there are only 4 (some argue 5) global players in this branch, so that our sample covers a representative share of the global market. Furthermore, the whole industrial sector is heavily affected by globalization on the market as well as on the manufacturing side. However, despite these global challenges, there is still a strong manufacturing focus in this heavy engineering 
industry and, thus, in our companies. Consequently, we assume that this importance of manufacturing exposes the companies quite intensively to what we defined as NE.

We applied mainly qualitative research methods. As an Anglo-German research team we developed interview guidelines and semi-structured questionnaires in German and English for managers involved in or responsible for change management measures in their companies. Our analysis is based on in-depth expert interviews with CEO's and managers responsible for change management at the MNC level (in the headquarters and its functional subunits) and at subsidiary level in both countries. Moreover, works councillors and union representatives of the Lifts \& Escalators industry were interviewed in both countries. In cooperation with our German partners we have conducted ca. 25 interviews so far, and studied official documents of these companies as well as newspaper and internet sources. In the interviews the following topics have been covered:

- general information about the company: questions were related to issues such as education and career background of the interviewee, company performance and profile, number of employees and qualification structure, assessment of the company's competitive situation

- $\quad$ past, present and planned reorganization and change management processes: questions were related to issues such as reasons for adopting these measure, actual aims of these measures, who was involved, obstacles and barriers to the change process, emergence of different views about these measures, the scope of these measures (whether it affects the MNC as a whole and other subsidiaries or just the local plant)

- starting points of change: questions were related to issues such as who initiated these measures, the role of the headquarters, the role and influence of local management, key actors in this process, who communicated with whom

- assessment of what are the positive and negative aspects of the plant's location in a particular national context: questions were also asked about the influence of the MNC's country of origin.

\section{The case studies}

In the following we will analyze the three MNCs in our sample in the light of our theoretical framework. This will first of all involve an analysis of the global, group-wide strategies as they manifest themselves in CMPs which are later implemented at the subsidiary level. The second and main step is to analyse how these global strategies and their 
global effects, as defined above, are realized and implemented in the different national contexts of Germany and Britain. This will involve a detailed analysis of the various elements of the respective national work systems of the subsidiaries. In this way we can identify how global effects are implemented on the national level and how this process is influenced and shaped by national effects.

\subsection{The American MNC}

\section{Global convergence as a continuous change process}

Amy shows the typical signs of an American company and throughout our field work, all interviewees perceived the corporate culture as being dominantly American. This applies not only to the general culture in the company but also to the style of management and decision making and use of American English, the latter point proving to be particularly significant for the German interviewees. As a division of the 57th largest American corporation, Amy is part of a typical (Chandlerian) multidivisional corporation with other divisions operating in technology-oriented branches, most notably the aircraft industry. Managers perceived the accounting and budgeting systems of the company to be the dominant coordination and control mechanisms throughout the multinational group. The shares of Amy's group are broadly scattered and performance on the stock market is seen to have direct influence on the short term plans of managers in the subsidiaries. This pressure is intensified by the fact that Amy is part of a conglomerate in which other divisions have suffered from downturns in general economic development which puts Amy under even more pressure to overperform the losses of those divisions in order to maintain the conglomerate's standing on Wall Street. A typical national characteristic, furthermore, is the fact that the main market for Amy is still the American home market, a fact strongly reflected by the interviews in both countries. Finally, this manifestation of the NE also applies to the strategy of the group which is regarded as extremely centralized, leaving only little space for bottomup initiatives. To sum up, in this American MNC we found all the major characteristics of what can be seen as the NE of America, which are backed up by numerous other research findings (e.g. Edwards et al., 2000; Edwards \& Ferner, 2001).

Analyzing these characteristics of the whole multinational group from the perspective of globalization, we see that the specific American NE strongly coincides with the GE. Amy clearly shows a strategy that works towards the convergence of markets and towards globally standardized products. Quite significant is the extent of insensitivity to national 
differences, which not only is visible in the enforcement of one common business language but, coincidentally, in the fact, that a country like the UK is organized in the same group as the Southern European countries, a fact which was commented on by managers as absurd and ridiculous. It is not surprising that it is especially the American NE that is identical to the GE if we analyze it from our theoretical perspective: the dominant factors shaping the business policy of Amy are economic and technological in nature. These are only influenced and shaped to a small degree by national contexts (“low-context”-variables).

This dominance of the GE within the entire MNC manifests itself in the CMPs which were being implemented in the entire group during the last three years. The German, as well as the UK interviewees, both stressed that, rather than having discrete changes in the work systems (like our Finnish company), change is an ongoing, constant pressure in the drive to greater efficiency in Amy. Given recent pressures from the multidivisional group, Amy is part of a big MNC rationalization effort and has decided to cut a significant number of jobs, reducing its global manufacturing plants by more than half (to 16) and reducing its research and development (R\&D) sites by more than two thirds to 6 worldwide (Iwer, 2000).

Major changes in the work system, however, took place on the technological level in the radical move towards standardized products and a world-wide one-brand strategy. This affected both the UK and Germany, where, as remainder of past acquisitions, Amy still operated in both with two smaller national brands until 1999. On the structural level, an interesting development was in the closure of the European headquarters of Amy in Paris and centralizing its functions in the HQ in the US. This can be interpreted as another clear manifestation of the GE as Amy further centralized the strategic elements of the work system and prevented stronger regional (in this case European) influences. Numerous managers in the subsidiaries particularly endorsed this view; Amy is regarded as being anxious not to create another center of power outside the US.

\section{The British subsidiary: getting rid of a 'poor' manufacturing image by developing a strong service orientation}

Moving on to the subsidiary level in the UK, we can identify one major CMP during recent years (apart from the realization of the one-brand strategy which was mainly achieved in conjunction with the other CMPs). Amy UK closed down all manufacturing sites and restructured the entire organization as a sales- and service-only organization with a centralized customer-care center. The UK subsidiary had been under performing for some time and, given the ongoing rationalization pressure within the whole MNC, it was clear that 
significant changes had to be made. However, the member of the board interviewed in the British subsidiary stressed that they had had considerable liberty in how to achieve a better performance. So the decision to close down the manufacturing sites in Britain was not taken in the US but in Britain itself. The reasons given for the decision were, on the one hand, the perception that "we in Britain” are not good at manufacturing and, most interesting, the fact that in the UK the institutional framework makes closures an easy option:

In the UK it is probably the easiest country in Europe to do different kinds of things. We really didn't have many obstacles, the way we approached it is obviously you have to go through the formal process, even in the UK information consultations, discussions, union agreement and then dealing with the individual employee and what we try to do is to make sure that the employees are treated as best as we can.

Human Resource Director Amy UK

The way the British subsidiary of Amy implemented the CMPs, which the HQ's performance requirements caused them to adopt, reveals that the NE has a significant influence. Furthermore we think that our data shows that the NE by no means works in a deterministic way but that there is a clear choice for actors in the subsidiaries as to which measures they take. So in the case of Amy, UK managers clearly took into account the constraints and weaknesses (poor manufacturing performance, low level of skill development, low social esteem for manufacturing and engineering in the UK) and the strengths (weak institutional barriers to redundancies, Anglo-Saxon in service-culture) in their decision. This is even underlined by the fact that another national characteristic was wilfully disregarded: managers were aware of the fact that closure of manufacturing in the UK is a significant competitive disadvantage since public and private investors in projects like the Jubilee Line in London or the Canary Wharf development still strongly cherish a "buy British” sourcing preference, which led to a loss in market share for Amy UK after the closure of manufacturing sites.

Looking at our research question and asking how GE and NE shape CMPs in the work system, the dominant impression is, of course, that the initiative to change clearly grew out of the pressure coming from the HQ. Pressure for global convergence, standardization and rationalization forms the starting point of change. When looking at the way different areas of the work system have been changed, however, we see that actors have a choice and that these choices reflect their perception of the national background. Major changes took place in the area of the technologies used and in the area of employment and human resources. In explaining the change from manufacturing to exclusively service technologies, all our interviewees clearly reflect the characteristics of the British business system (as 
“compartmentalized”, Whitley, 1999:60), especially the low level of skills, low productivity of manufacturing and the trend towards service industries in general. Furthermore, the weak regulatory environment allowed global strategies to have a very significant impact on the subsidiary. So we can conclude that in a business environment characterized by weak national institutions, the GE has a rather strong impact. However, local managers have choices in implementing CMPs and these choices reflect the actors' perceptions of the major strengths and weaknesses of the national business environment.

\section{The German subsidiary: cultivating German 'virtues' in an US-American MNC}

On the surface, our research in the German subsidiary of Amy shows a quite significantly different picture. The most striking difference is that - apart from cutting the second minor brand besides "Amy" - there has been no identifiable discrete CMP in the two manufacturing plants as well as in the administrative center of Amy Germany. Despite considerable pressure from the HQ level, the German managers responded to questions about change more by referring to "general”, “continuous” or "permanent” pressure to change rather than actual concrete measures taken within the last years. It is exactly in this ongoing incremental change process that the most significant influence of the GE is visible. It manifests itself at work system level most clearly in the organizational structures and processes. The German chairman boasted that they have "no organization chart” as the company is a "dynamic" entity not to be restricted by formal hierarchies, a view which managers identified as a clear American influence. The same applies to other structural elements of the work system within the company, most notably the coordination- and control system, which is clearly labeled “American” in its emphasis on rule by financial benchmarks, budgets and performance targets. The same applies to the short-term orientation of business decisions which German managers perceive as particularly constraining and inappropriate.

We have 80000 elevators in maintenance. I cannot renovate them all at once. That is an investment program for 10 years. And given the short-sightedness of our American friends they simply do not take any notice of this situation. You know, we are now forced to think much more short-term in introducing new procedures.

Director Service Center Division, Amy Germany

On the other hand, they see themselves as having considerable liberty with regard to the methods and technologies by which they realize the goals of the HQ. It is exactly this which leads to the most significant differences between the work systems of Amy in the UK and Germany. The most significant differences lie in the technological area and the structure 
of the human resources. Germany has two production sites, one producing mostly key electronic components for the entire multinational group and another specializing in heavy duty escalators for which it is the only remaining production unit within the whole multinational group. Furthermore, they have extensive R\&D capacities at both plants so that the German managers regard their country as the leading unit worldwide in the entire multinational group on the technological level. When asked for the reasons for this situation, all interviewees refer to the textbook features of the German business system: high level of skills, excellent vocational system and high productivity. It even appears in some of the interviews, especially on the second hierarchical level below the national board, that they regard themselves basically as a German company that still has its roots in the company Amy acquired no less than 50 years ago. So, on the work system level, Amy Germany still appears very strongly to be a German company, that happens to be part of a wider US-conglomerate. This does not only apply to the technological aspect, also the human resource practices reflect the same strong national orientation, perhaps with the exception of an "Amyuniversity program”, which leads to international exchange of young high potential employees within the multinational organization.

Comparing the UK and German subsidiaries we tend to the conclusion that both cases show what Child named the "dialectic" influence of globalization in organizations. Amy has a considerably tight global strategy which results in a significant GE on the national subsidiary level. Nevertheless, national contexts have very strong implications in realizing the global strategy, which in the end stimulates rather than threatens NEs. Within the global group, the national peculiarities are "used" in ways in which they best contribute to the overarching corporate goals. Since the NE in Britain and Germany is quite diverse, the resulting organization of the subsidiaries and the work systems are equally diverse, leading to an example of the new British service economy on the one hand and to a typical German manufacturing and technology driven organization on the other.

\subsection{The Finnish MNC}

\section{Finnish MNCs: from forest to free trade?}

When looking at the CMPs in the entire group of Jukka we had quite a number of ambivalent findings, which seem to reflect relevant transitions in the contemporary Finnish economy. As Lilja et al. have pointed out, the entire Finnish business system is characterized by the fact that its roots lie in the forest industry. This has led to a number of very strong 
characteristics in the national context, the most important ones for our study being orientation on ownership and long term profits ("patient capital”), strong priority for technological innovation and a strong preference for consensus and cooperation in business policies, especially with regard to employees (Lilja, Räsänen, \& Tainio, 1992, see also Laurila \& Ropponen, 2001). However, these characteristics have been recently coming under considerable pressure to change. Finland has opened its economy strongly towards global markets, which has especially significant consequences for the ownership structures of companies (Tainio, 2001). Moving from bank- and family-owned patterns to a shareholder dominated ownership structure, the Finnish business system is presently undergoing a significant shift towards "low-context” influences of international capital markets. Consequences include a “financialization” (Tainio, 2001) of organizations, short term horizons for business decisions and a stronger focus on shareholders' rather than employees' interests.

This transition in the Finish national business system is quite visibly reflected in the strategic orientation of Jukka. The company is still owned by a family that controls $2 / 3$ of the voting shares. Though the recent strategy towards global standardization of management processes made it necessary to relocate the HQ to Belgium, the company still has a HQ in Finland where the owners live. This is even more bizarre in the light of the strong pressure towards standardization, harmonization and rationalization that generally dominates the strategies of Jukka as a whole. Furthermore, there is a clear focus on technological excellence and Jukka prides itself on being the first mover in several key innovations in the lift and escalators industry (e.g. the machine-room-less elevator). There is a clear focus on technological excellence; in terms of technology Jukka wants to be the "best in town", as one of the senior executives put it. This orientation is very typical for the Finnish national business system as recent studies on Finnish high-technology companies such as Nokia and others have identified (Lilja \& Tainio, 1996). This strategy, however, contrasts with the goal of developing a mass product in the form of a standardized global escalator which to some extent contradicts this strive for technological excellence. Finally, with regard to consensus and employee orientation the same transition manifests itself in Jukka's approach. Various interviewees stress the fact that Finnish managers indeed have a rather inclusive approach to management:

A Finn would never bang on the table. They simply don't do that. A decision in Finland is not taken, it just emerges somehow. If you tell that to a German, he'd say: 'I just can't imagine that.'. 
On the other hand, Jukka is increasingly seeking to change this style of governance to one which is clearly oriented to the achievement of the strategic financial goals of the company without any compromise with stakeholders such as employees. Short term constraints increasingly force the managers to move away from this Finnish style of consensual decision making. The following quote shows quite clearly the learning processes of Finnish managers in adapting their national culture to the constraints of a globalizing organization.

Well, there are ways to overcome that [resistance to change], it takes a lot of information, a lot of hand-holding and so on. And then there are some people who will even never, just never get convinced and then it's those people typically who become the casualties of the war. But, of course, it depends on how much time you have in your hands to make changes. OK, if you have a lot of time then you really can go deep into the individual issues of people and so on. If you don't have it, unfortunately, sometimes companies have to make shortcuts and that can be very tough.

Managing Director (Finnish nationality), Jukka Germany

This quote reveals quite clearly the emerging contemporary pattern of communication and decision-making in Finnish MNCs as one where a strategic framework is set by the top (mostly Finnish) managers of the HQ and of the local companies.

Discussion and participation of local managers about the ways in which these measures can be applied more smoothly are welcomed. Thus, there is some space for participative decision making at the local subsidiary level, but less possibilities to alter the basic ideas behind the change management strategy. These issues are not discussable, but should be locally acknowledged without any compromise.

The influence of globalization on the national Finnish business context can be traced in the corporate strategies of the multinational group of Jukka. Although, as we pointed out, certain characteristics of the Finnish national context still prevail, Jukka is a company that deliberately sets out to be a global company and its strategies clearly reflect the orientation to the "low-context" environment of global markets and global manufacturing systems. This is presently the dominant force in the corporation's CMPs. The group has had its most significant growth during the last 10 years through acquisitions, so that the dominant strategic orientation is the global integration of the MNC. There is a clear view of globalization as the dominant imperative of all impending change processes in the

\footnotetext{
* This assessment was given in a discussion of this research by Professor Kari Lilja, Helsinki School of Economics, during the 'ESRI Thematic Research Workshop on Changing Contextual Constructions of Economic Rationality’, September 15-18, 2001, Portoroz, Slovenia.
} 
corporation, as the following quotes from three senior executives in the HQ, in Germany and Britain show:

'Global' means trying to standardise not only products but processes throughout the world, operations of the corporation.

Globalisation does lead to convergence eventually, it's not divergence, ...convergence definitely.

The CEO calls it 'globalisation' but I see it as a "harmonisation", harmonisation of business processes.

A further indication of this strong shift toward low-context strategies is the fact that many respondents characterized the organization as strongly "controller" driven and it appears that Jukka is trying to develop its strategies towards a level of global integration at which a company like Amy has already been operating for quite some time.

\section{Global change management processes}

The strong pressures towards globalization manifest themselves in the ongoing CMPs in the company. Both subsidiaries had to implement what we identified as three major CMPs, which led and are still leading to major changes in the work systems of the respective subsidiaries. First, there is the implementation of what is called a "Jukka-model" of doing business. Basically, this concept differentiates the organization into a part that is oriented towards the market ("front line”) and a part that is oriented towards manufacturing ("supply line”). The aim of this model is to standardize all business processes world wide.

Furthermore, it aims to abolish national entities and subsidiaries as such, and orientate the corporation either towards the (globally integrating) market or to the economic rationalities of the internal production processes. Consequently, this model manifests the MNC's orientation towards low-context environments of global economic and business rationalities. The second major CMP operates along the same lines, this is the global introduction of a standardized financial reporting and controlling system based on tools provided by the software company SAP. Apart from encouraging further convergence of global business processes, this CMP shows the strong orientation towards financial performance indicators as the central tool for management within the MNC as a whole. The third significant CMP is the implementation of a world wide standardized escalator product line, which again is an expression of the corporate drive towards convergence and harmonization. However, it was this decision which had quite diverse effects in the two national subsidiaries of our sample. 


\section{Jukka in Germany: national specific patterns of resistance to change}

The implementation of the new “Jukka model” and the implementation of SAP both processes being implemented more or less simultaneously - had a massive influence on the work systems at Jukka's German operations. This pertained especially to organizational processes and the technologies used. The general impression from our research is that the German subsidiary was extremely successful in resisting and obstructing these processes from the very beginning with the result that Germany became the very last entity of the entire multinational group where these changes were being implemented, leaving senior managers still struggling with major problems at the time of our interviews. The reasons given for this from the perspective of the Finnish HQ were twofold: On the one hand, they see the “Jukka-model” as codifying the (Anglo-Saxon) orientation towards management processes which strongly clashes with the German functional approach to management. This could well be interpreted as a clash of GE with NE in a major part of the subsidiary's work system. The second group of reasons was more politically motivated. There was a strong resistance among the senior management of the German company, which was an independent, profitable company before being taken over by Jukka in 1996. Finally, the enforcement of the “Jukka-model” and the new software system was only achieved by a (almost) complete replacement of the first and second layers of management in Germany by “Jukka-ites” (as one interviewee put it), who were senior executives from the multinational group, the majority being Finnish nationals.

This process sheds specific light on our research question of how GE and NE are intertwined in MNCs. The power base of the German management clearly lay in the fact that certain parts of the work system, the R\&D know-how, the engineering capacity and the highly skilled and efficient production workforce were key to Jukka's global strategy. Germany, though not a "hot-bed” of Jukka culture (quote from a HQ representative), provides the entire multinational group with engineering know-how and is the leading in $R \& D$ location world-wide. These typical textbook features of a company reflecting the strength of the German business system can clearly be identified as NEs (Warner and Campbell 1993). German managers were quite skilful in playing on their specific, nationally flavoured power resources. So, with regard to the third CMP of introducing a global standardized escalator, they were able to ensure that their location in Germany became one of the three plants world wide to produce this new standardized product. In this, the situation in the German Jukka plant resembles the situation in the German Amy plant: national strengths are explicitly not "standardized", or "harmonized" out of existence, but there is a 
struggle to integrate them into the global trend towards convergence of management systems. This struggle can be very well observed in our data: Jukka wants to preserve German know-how and expertise on the one hand, but wants to make them fit into standardized, globally harmonized work systems. The case of Jukka reveals the considerable need for the use of power in order to achieve this transition in a strong institutional and cultural context. Strong national resistance, by the way, was not only visible in the processes described, the German codified system of industrial relations, most notably the works council (Betriebsrat), also proved to be a major obstacle in implementing the new work system.

The (preliminary) solution to this conflict was the massive introduction of Finnish executives, in other words, a use of organizational power in order to neutralize the subsidiary power based on knowledge and skills. This strong position of a group of Finnish nationals, sometimes referred to as a "Finnish mafia", is also reiterated in other studies on the Jukka organization (Marschan, Welch, \& Welch, 1999) However, the GE which becomes manifest in this forceful implementation of new work systems in Jukka Germany still has a national flavour, reflecting the transitory state of the Finnish business context of Jukka's HQ: a powerful tool in "getting a grip” on the German subsidiary is the shared language and cultural values of the new management team:

One could well say, that given our size and role in the global market, we have an overrepresentation of Finnish managers, that's for sure. I am certainly an exception here...ehh... one of the few cases in such a position...ehh... as a non-Finnish [...] I know of some information which is only discussed amongst the Finnish management and with me [...] Well, the highest level of secrecy is: 'only among Finns', and after that, some confidents might be included [laughs]...

Technical Director and Director R\&D (German nationality), Jukka Germany

This finding - again confirmed by other projects on Jukka (Marschan, Welch, \& Welch, 1997; Marschan et al., 1999) - reveals the rather paradoxical situation, that even in implementing globalization, and thus trying to decrease, if not abolish, the relevance of national contexts in the management processes, it is the very national background of the actors of globalization which becomes a key resource in doing so. Jukka's management strategies in this sense are fuelled in the most powerful way by those very factors, whose abolition is the explicit and avowed goal of the strategy itself.

\section{Jukka in the UK: Why are they still manufacturing there?}

One of the most striking research questions during our field work focused on the fact that Jukka UK runs the only plant in the UK in the whole lift\&escalator sector that still 
manufactures on a large scale (except from Karl-Heinz UK that still produces a very few highly customized and unique lifts for the upper market segment). When comparing Jukka's subsidiary in Britain with the one in Germany, it is striking how little difference there is between both companies, given the different national contexts of both locations. The reason lies in the fact that the British subsidiary has been a part of the German subsidiary of Jukka (and its predecessor) since 1973. Consequently, the Managing Director of Jukka's plant in the UK called his company a "German" company, which particularly applies to the work system in the UK. Over a period of more than 10 years after the acquisition the German owner built up a very efficient production and engineering plant in the UK, investing heavily in vocational training of workers, production facilities and engineering skills. In fact, still today the British technicians in the plant use German measures, standards and much of the “technical language” is German as well. This strong influence of the former German owners established a subsidiary whose entire work systems, especially in the area of the technologies used and the employment practices and policies, in no way reflect the peculiarities of the British national context. Consequently, the resistance against the CMPs of Jukka was equally as high as it was in Germany, and again, it was only the retirement of the Managing Director in 1999 which enabled the massive reorganization process to introduce the "Jukka-model" and the new software systems. In particular, the engineering and manufacturing staff perceived the new policies as "edicts" imposed on them so that the globalization strategy of Jukka had to be implemented quite forcefully. However, our impression, especially when interviewing the new Managing Director, was that in the end senior management in the UK had identified considerable strategic advantages for the UK operations in complying with the global strategies. The engineering and manufacturing know-how in the UK is proving to be a powerful asset for its role within the entire multinational group, now it is no longer a part of a German SME (mittelständisches Unternehmen), but a direct subsidiary of a global group. This led to the decision to produce all heavy duty and specialized escalators within the entire Jukka group in the UK. This massive change in the structure of the work system, most notably in the products and the markets of the company, puts the British plant in a position of relative power.

One might well ask about the whereabouts of any national effects, especially from the British context, in the CMP that took place in the UK. Given the situation that Jukka UK was such an "un-British" company in the first place, these effects were rather difficult to trace. However, we found some insightful developments in the course of the implementation of the CMPs in various areas of the work systems. One of the reasons for concentrating 
heavy duty production in the UK was the fact that the clients for these products - the London Underground and BAA counting among the most important ones - still follow very strongly a "buy-British" philosophy. In fact, Jukka UK explains its market share of more than $50 \%$ in the home market by the fact that they are the only company that still manufactures escalators in the UK at all. Apart from that, the implementation of the SAP system in the UK went considerably smoothly and quickly because the key actor in this change process was not (as in Germany) an engineer but a senior financial manager. It appeared that Jukka UK in this aspect reflects a typical characteristic of the British business system compared to its German counterpart (Lane, 1992: 86): the dominance of financial managers over technical/engineering managers in companies, which we have already identified in the Amy UK organization. It was the general fear of the technical staff in the UK that in the course of their integration into the world-wide group, the strengths of the plant, especially in engineering and manufacturing, would deteriorate. In other words, integrating the plant into a "low-context" global strategy toward convergence of management practices might expose them more strongly to the "low-context" British business environment as well. For instance, they were already experiencing some problems in attracting skilled workforce to the shop floor and maintaining the high skill level at the plant in the UK.

Another aspect, finally, sheds light on a very specific influence of nationality in the context of a globalizing MNC. The Managing Director of Jukka UK explains the growing strategic importance of his unit within the whole MNC:

On the strategic level, that's quite interesting, we probably have a position and influence much greater than you might expect. The reason is because the working language of the company is English and of course we are English so the consequence of that is that the Finns are very logical and they say, well if you want to do something internationally and you need to get the message over properly then use an English guy because he speaks the language, hopefully, the best. [...]Even in the US they use English people, not US people. So they kind of capitalise on the language skills of the people here.

So in the concrete case of a British plant of a MNC there seems to be considerable gain in fact that globalization leads to convergence towards a "global" culture which ultimately - happens to have their own (English) national language as its base. Generally speaking, we get the impression from our data that globalization empowers those national backgrounds which have already been successful in building up competitive advantages in those parts of their work systems that have been particularly influenced by low-context business environments. 


\subsection{The German MNC}

\section{German MNCs: the 'highly decentralized' company?}

In a certain sense the German member of our sample provides the least evidence of globalization forces. Looking to the strategies of the MNC as a whole, our data definitely show less evidence of any moves towards global convergence. Furthermore, like in Amy, Karl-Heinz had no concrete CMPs implemented throughout the whole multinational group. Some change management initiatives can be identified but these were part of the general goals of achieving more efficiency rather than being standardized and centrally driven change management processes as in Jukka. Karl-Heinz appears to be a classic text book German-style company and shows an extensive number of characteristics typical of a large German conglomerate with a powerful engineering culture (Warner \& Campbell, 1993). However, in the multinational group there have been some slight indications of global convergence: the group introduced a standardized system recently for all subsidiaries' reports to the HQ in Germany. Furthermore, there is some awareness of the need for a global market presence, which led to the acquisition of one of America's biggest lift\&escalator companies. This resulted, furthermore, in the first non-German board member - the first step, perhaps, in “denationalizing” the leadership structure.

Apart from that, however, Karl-Heinz has a highly decentralized governance system with a network of rather loosely knit national companies, which in their respective countries work in accordance with the (perceived) national business context. There is no central R\&D, no global standardization of products and even though the general focus is on the more expansive, upmarket product range this is not a generally enforced strategy throughout the group, which allows for different market strategies in countries like, for instance, France. Senior management justified this approach by stressing extensive national differences in market requirements, production systems and, last but by no means least, language barriers, which allegedly would make a more globalized approach to leadership within the multinational group impossible. As long as the budgeted financial targets are met nationally by subsidiaries, they are granted a maximal amount of liberty.

Recent change processes included a merger of Karl-Heinz's German mother with another large German conglomerate but this did not affect the lift and escalator part of the company, not least because the dominant group of institutional shareholders could not agree on a common strategy for the entire Konzern so far (an ongoing process for more than 4 years now). 
Moving on to the German subsidiary of Karl-Heinz, there have been some CMPs such as a new rationalization of the production site at their manufacturing plant and a concentration of R\&D at the company's main location in the South of Germany. These were justified more by local technical rationalities and a general drive for more profitability rather than being the expression of a centrally imposed and enforced strategic orientation. As a general conclusion, it seems that Karl-Heinz in Germany is a fairly independent unit which works as a large medium-sized (mittelständisch) enterprise with most typical characteristics of a German company.

\section{Karl-Heinz in the UK: the most "British" subsidiary of our company cases}

Significant changes have taken place in the British subsidiary of Karl-Heinz during the last 3 years. Shortly after the acquisition of a medium-sized company in the UK, KarlHeinz closed down its entire manufacturing and reorganized the work system into a salesand service-only organization. Our interviews with different actors in this change process revealed that the main initiative for change and the key actor in this process was the Managing Director of Thyssen UK. Though a German owned company, Thyssen UK was transformed into a company which almost typically reflects key textbook features of the British business context with rather individualistic orientated change management approaches, top managers who are highly experienced in job-hopping and rather short term and financial driven business planning perspectives (Tayeb, 1993). Apart from the need to bring the subsidiary back into profit, the British subsidiary had complete freedom in how they realized this aim. There was absolutely no interference from the HQ in any way, the guidelines from the HQ for the subsidiary's operation were said to fill not more than "maybe three to four sheets of paper".

Consequently, the work system was changed in a very short time. In sales, the shift went completely towards high-value products, leaving a small workforce to do customized work to meet client's specific wishes. For the rest, the formerly centralized service organization was completely transformed into a network of regional service centers which can flexibly react to clients' wishes. Interestingly, the service is not only offered to clients of Karl-Heinz but the company offers service to all makes of lifts and escalators. The main reason given by the Managing Director for these changes were that "we are not good in manufacturing” and that service in Britain is a very profitable business, not least because British law, unlike in Germany, requires users of lifts and escalators to have their equipment serviced on a regular basis. With regard to new products, the UK subsidiary buys them on 
the internal Karl-Heinz-market from Germany, Spain, Italy or France. In this sense, the multinational group and its resources, though not forcing the British company into anything, had an enabling role for their strategy.

The entire process of communication and control in the reorganized company appeared to be very informal, personalized and tailored to the Managing Director, which was confirmed by our interviews with various actors in the organization. The changes also pertained to employment issues where about $12 \%$ of the workforce had to be laid off. "To fire persons went much faster than the German headquarters expected”, the Managing Director reflected on this, which reveals - as the entire CMP does - a strategy which is quite successfully adapted to the low level of institutionalization of the British business system. In more general terms, the British subsidiary prides itself not only in having come to a solution which is perfectly adapted to the requirements of the domestic British market, but also it perceives itself as a leader in terms of "organizing an efficient service organization" for the entire Karl-Heinz group. Though their approach "became a horror for German managers", they regard their "model” as currently being implemented in Germany and the US. However, though the British subsidiary regards itself as successful and influential, our data from Germany did not confirm this assessment.

\section{The works council: Europeanization of industrial relations}

The results of our search for globalization in terms of convergence and harmonization of strategies and management practices in Karl-Heinz have been rather thin. However, there was evidence that the reorganization process of the British subsidiary also led to the institutionalization of a works council. This was explained as being a "German initiative” because "we are not good at these things" in Britain. As part of a big German “Konzern” Karl-Heinz also has a works council for all operations in the UK, the head of which was a member (and subsequently the vice-chairman) of the European works council of Karl-Heinz. He explained the history of the British works council, which includes the works council in the lift and escalator subsidiary of Karl-Heinz in Britain:

We have got the European works council at the concern level [...] they did actually influence the English management because all of the French, Spanish, German and Italians had works councils. It was only the English that didn't. So they used the influence from outside the UK. When the UK management went to meetings where the other managers were, they actually used that influence to get works councils in the UK. I am trying to use the influence of IGM [the German metal worker's trade union] to try and get a formal or even an informal meeting, twice a year meeting with 
all the UK reps. [...] It is very difficult because the English management do not want to know.

And further:

They [the British management of Karl-Heinz] have got no concept of exactly what that man does, they have no concept of what a chairman of a works council does, they have no concept of me being the first ever, full time union man in this company. We have never had one before.

The British works council obviously is an element of the work system of the British subsidiary which clearly reveals what we would rather define as a Europeanized (transnational) effect rather than a global (in terms of world-wide) effect. It would be interesting to investigate whether and what kind of industrial relation system has been introduced within the recently acquired US-American company and if this effect really has a global (in the sense of world-wide) spread. The German institutional background, backed up by a convergent European legislation in the area of worker's rights leads to - at least on the European level - transnational convergence of standards and policies in the area of industrial relations. This development forces the British subsidiary of Karl-Heinz to integrate a participatory element into its work system that is clearly imposed by the multinational group onto the British subsidiary. This conclusion is further backed up by the structure of this part of the work system, as the chairman of Karl-Heinz's British works council explains:

I was in contact with my German colleagues and I actually knew a lot more than I can say, I knew more than most of my managers. I have actually been in a position where I came back from Germany and I saw our chief executive, and I told him something that even he didn't know. Which he was not very happy about, and it concerned this company. [...] Obviously some of my colleagues are on the supervisory board of the Konzern. They get to see documents before the division and the division gets to see documents before they go outside of Germany. [...] I have a far better reporting structure from Germany to England, than I do from England to England.

The European transnational network of works councils appears to be a "parallel” organization within the entire multinational group which uses the forces of globalization to achieve its goals, most notably in the UK, where the national business system actually strongly opposes these forces. Nevertheless, it is quite amazing to see that globalization, given the European convergence in legislation, helps to implement a stronger organizational structure of the workforce than it would normally be the case. This seems to be remarkable, though maybe anecdotal, evidence that globalization does not in every case imply a "race to the bottom" in social standards, which is normally seen as one of its main consequences (Scherer \& Smid, 2000). Furthermore, it is possible to identify a specific “German” element in this process: The British chairman of the works council has informal access to strategic 
information, since the German Montan Mitbestimmung assigns works council members the right to sit on the supervisory board (Aufsichtsrat) and thus participate in strategically important decisions. This informal communication flow provides the British works council with a very powerful position because the transnational organization of the works councils is far more centralized than the - as discussed - extremely decentralized organization of the MNC as such, which includes a very slow and multilayered communication and control system with a considerable amount of organizational slack.

\section{Conclusion}

We close our analysis by a number of concluding remarks on our research question about whether and how global effects and national effects intertwine in change processes in the work systems of MNCs (see Figure 3 as an overview).

\begin{tabular}{|c|c|c|c|}
\hline & \multicolumn{3}{|c|}{ Evolution ?? } \\
\hline & Karl-Heinz & Jukka & Amy \\
\hline $\begin{array}{l}\text { Type (following } \\
\text { Bartlett/Goshal) }\end{array}$ & „multinational“ & $\begin{array}{l}\text { From multinational } \\
\text { towards } \\
\text { global/transnational }\end{array}$ & "global" \\
\hline $\begin{array}{l}\text { Role of subsidiaries } \\
\text { in UK and Germany }\end{array}$ & $\begin{array}{l}\text { Textbook: exploiting } \\
\text { local opportunities }\end{array}$ & $\begin{array}{l}\text { Textbook: } \\
\text { Implementors }\end{array}$ & $\begin{array}{l}\text { More than simple } \\
\text { "implementors“ }\end{array}$ \\
\hline $\begin{array}{l}\text { Development/diffusio } \\
\mathrm{n} \text { of knowledge }\end{array}$ & $\begin{array}{l}\text { Textbook: developed } \\
\text { and retained within } \\
\text { units }\end{array}$ & $\begin{array}{l}\text { Strong role of } \\
\text { subsidiary in } \\
\text { knowledge creation }\end{array}$ & $\begin{array}{l}\text { Strong role of } \\
\text { subsidiary in } \\
\text { knowledge creation }\end{array}$ \\
\hline $\begin{array}{l}\text { Role of national } \\
\text { backgrounds }\end{array}$ & Decisive & $\begin{array}{l}\text { Partly resistant to } \\
\text { global strategy }\end{array}$ & $\begin{array}{l}\text { Operational liberty of } \\
\text { subs. makes national } \\
\text { backgrounds } \\
\text { important }\end{array}$ \\
\hline Future trends? & $\begin{array}{l}\text { Will try to remain a } \\
\text { higly flexible, } \\
\text { successful } \\
\text { organisation, leader } \\
\text { in upmarket segment }\end{array}$ & $\begin{array}{l}\text { On the way to } \\
\text { convergent } \\
\text { organization-wide } \\
\text { work systems? }\end{array}$ & $\begin{array}{l}\text { Convergent } \\
\text { organization-wide } \\
\text { work systems are } \\
\text { not to be expected }\end{array}$ \\
\hline
\end{tabular}

Figure 3: Comparison of the three case studies following Bartlett \& Goshal (1989: 65)

Our research seems to shed light on the potential of a more process and actor focused analysis, which is clearly visible if we take the two extreme cases of our spectrum. On the one hand, Amy could be seen - to use the Bartlett/Ghoshal (1989, p. 65) evolutionary framework of organizational characteristics of the transnational - rather as a "global company”, where we would expect a significant amount of convergent, transnationally 
homogeneous business practices. However, looking at the work systems and the change processes on this level in its German subsidiary, we find a nearly textbook-like "German” company. The stunning contradictory - if not “dialectical” (Sorge, 2000) - finding in our research seems to be that the more globalized the strategies and structures of a MNC are, the more it allows for and relies on national specifics to play a key role in its global portfolio of national subsidiaries. From this perspective one could even argue that globalization ultimately reinforces the importance of different national contexts. National business system patterns become visible when local managers at Amy UK gave reasons as to why they were relieved to get rid of their low performing manufacturing units in the ongoing change management process and focus their business strategy wholly on service and sale functions. Moreover, the structuring of the work system of the German counterpart subsidiary and their relatively powerful position in the MNC decision-making process are indicators of German business systems patterns. The geographical HQ function of Amy in Germany, its increased geographical responsibilities (such as in Eastern Europe) and its strong position in strategic tasks of the MNC as a whole, such as in $\mathrm{R} \& \mathrm{D}$, are not simply power resources as recently shown (Geppert et al., 2001b). Amy Germany’s work systems design can be clearly related to the German institutional context.

On the other side of the spectrum there is a company such as Karl-Heinz which again in reference to Bartlett/Ghoshal's framework (Bartlett et al., 1989: 65) - could be labelled as a "multinational company" and appears as a rather laid back, decentalized organization dominated by its specific national background and local opportunities. The analysis of Karl-Heinz's operations in the UK, however, reveals a highly flexible, innovative organization efficiently adapting to the local specifics of the market and focusing on highquality upmarket products and services. One would not expect the potential for innovative change processes on the work systems level in such a MNC that - following traditional categorizations in the literature - would be regarded as a rather inefficient, outdated organizational structure. Instead, our data leads us to argue that the organizational design of the Karl-Heinz and, especially, its German subsidiary significantly reflects the German Business system patterns. Thus the strong strategic orientation of the lifts and escalators division of the German MNC towards the customized competitive quality market segment, to which not only the German, but also the British subsidiary is committed, shows significantly its institutional origins. In this sense, it is no surprise that it is not the American multinational which is the leader in this upper market segment, but the German multinational group. Moreover, the highly decentralized governance structure of the MNC not only 
permits the British plant to be very British in its work system design, but undoubtedly allows the German counterpart to operate as a German textbook case company with craft-type and rather product-led than market-led work systems and highly skilled and professional managers (Warner et al., 1993).

In the middle of this spectrum we would position Jukka where one might see the strongest trend towards a real global convergence of organization-wide work systems. From a superficial grasp, this case might point in the direction of Mueller's argument of identifying a third, distinct “organization effect” next to GE and NE (Mueller, 1994). Nevertheless, our case study shows that even the strong organizational implementation of the GE is by no means an independent, deterministic effect. It faces strong resistance from constraints based on the history of the company (UK) or effects based on the national business system (Germany). It is an open point in which direction the strong standardization strategy of Jukka will finally move the MNC in the end.

\section{References}

Bartlett, C. \& Ghoshal, S. 1989. Managing across borders: The transnational solution (2 ed.). Boston: Harvard Business School Press.

Becker-Ritterspach, F., Lange, K., \& Lohr, K. 2001. Do European corporate coordination and control systems converge?, Paper presented at the founding conference of EURAM. Barcelona.

Birkinshaw, J. \& Fry, N. 1998. Subsidiary to develop new markets. Sloan Management Review: 51-61.

Birkinshaw, J. \& Hood, N. 2001. Unleash innovation in foreign subsidiaries. Harvard Business Review(3): 131-137.

Boddewyn, J. J. \& Iyer, G. 1999. International-business research: Beyond déjà vu. Management International Review, 39(Special Issue 1999/2): 161-184.

Buckley, P. J. \& Chapman, M. 1999. Theory and method in international business research. International Business Review, 5(3): 233-245.

Child, J. 2000. Theorizing about organizations cross-nationally. In R. B. Peterson (Ed.), Advances in international comparative management, Volume 13: 27-75. Stamford/CN: JAI Press.

Child, J. \& Yan, Y. 2001. National and transnational effects in international business: indications from Sino-foreign joint ventures. Management International Review, 41(1): 53-75.

Doremus, P. N., Keller, W. W., Pauly, L. W., \& Reich, S. 1998. The myth of the global corporation. Princeton, NJ: Princeton University Press.

Edwards, T. \& Ferner, A. 2000. The renewed 'American challenge': a review of employment practices in US multinationals, Paper presented at the 50th British Universities Industrial Relations Association Annual Conference. Warwick.

Edwards, T. \& Ferner, A. 2001. Wall Street, 'short-termism' and the management of labour in American multinationals, ESRC Transnational Communities Programme Conference. Warwick. 
Geppert, M., Matten, D., \& Williams, K. 2001a. The design of work systems in national subsidiaries of multinational companies: globalisation, national institutions and managerial choice. Swansea: EBMS-Working Paper 2001/7.

Geppert, M., Williams, K., \& Matten, D. 2001b. The social construction of change management in MNCs: an Anglo-German comparison. Swansea: EBMS-Working Paper 2001/9.

Held, D. \& McGrew, A. G. 2000. The global transformations reader: An introduction to the globalization debate. Cambridge: Polity Press.

Iwer, F. 2000. Innovationstrends in der Aufzugsindustrie und Folgen für die Beschäftigungssituation. Projektabschlußbericht. Stuttgart: IG-Metall.

Lane, C. 1992. European business systems: Britain and Germany compared. In R. Whitley (Ed.), European business systems: 64-97. London: Sage.

Lane, C. 2000. Understanding the globalization strategies of German and British multinational companies. In A. Sorge (Ed.), Embedding organizations: societal analysis of actors, organizations, and socio-economic content: 188-208. Amsterdam/Philadelphia: John Benjamins.

Laurila, J. \& Ropponen, M. 2001. Sustaining homogeneity in the forms of foreign expansion: some evidence from the Finnish-based forest industries, ESRC Transnational Communities Programme Conference. Warwick.

Lilja, K., Räsänen, K., \& Tainio, R. 1992. A dominant business recipe: the forest sector in Finland. In R. Whitley (Ed.), European business systems: 137-154. London: Sage.

Lilja, K. \& Tainio, R. 1996. The nature of the typical Finnish firm. In P. H. Kristensen (Ed.), The changing European firm: 159-191. London: Routledge.

Marschan, R., Welch, D., \& Welch, L. 1997. Language: the forgotten factor in multinational management. European Management Journal, 15(5): 591-598.

Marschan, R., Welch, D., \& Welch, L. 1999. In the shadow: the impact of language on structure, power and communication in the multinational. International Business Review, 8: 421-440.

McGrew, A. G. 1997. Globalization and territorial democracy: An introduction. In A. G. McGrew (Ed.), The transformation of democracy? Globalization and territorial democracy: 1-24. Cambridge: Polity Press.

Morgan, G., Kelly, B., Sharpe, D., \& Whitley, R. 2001. Multinationals as organisations, ESRC Transnational Communities Programme Conference. Warwick.

Mueller, F. 1994. Societal effect, organisational effect, and globalization. Organization Studies, 15(3): 407-428.

Nohria, N. \& Ghoshal, S. 1997. The differentiated network. Organizing multinational corporations for value creation. San Francisco: Jossey-Bass.

Ohmae, K. 1990. The borderless world: power and strategy in the interlinked economy. New York: Free Press.

Parker, B. 1998. Globalization and business practice: managing across boundaries. London: Sage.

Prakash, A. \& Hart, J. A. (Eds.). 2000. Coping with globalization. London: Routledge.

Rank, O. 1999. Rollentypologien von Tochtergesellschaften.

Rugman, A. M. 2000. The end of globalisation. London: Random House.

Scherer, A. G. \& Smid, M. 2000. The downward spiral and the U.S. model business principles - Why MNEs should take responsibility for improvement of world-wide social and environmental conditions. Management International Review, 40: 351-371.

Sorge, A. \& Streeck, W. 1988. Industrial relations and technical change: The case for an extended perspective. In W. Streeck (Ed.), New technology and industrial relations: 1947. Oxford: Blackwell. 
Sorge, A. 1993. Arbeit, Organisation und Arbeitsbeziehungen in Ostdeutschland (Antrittsvorlesung 24. Mai 1993). Berlin: Humboldt-Universität.

Sorge, A. 1995. Cross-national differences in personnel and organization. In J. van Ruysseveldt (Ed.), International Human Resource Management. An integrated Approach: 99-123. London: Sage.

Sorge, A. 1996. Societal effects in cross-national organization studies: conceptualizing diverstiy in actors and systems. In P. H. Kristensen (Ed.), The changing European firm: 67-86. London: Routledge.

Sorge, A. 2000. The diabolical dialectics of societal effects. In A. Sorge (Ed.), Embedding organizations: societal analysis of actors, organizations, and socio-economic content: 37-56. Amsterdam/Philadelphia: John Benjamins.

Tainio, R. 2001. Effects of foreign portfolio investors on Finnish companies and their management, Paper presented at the 17th EGOS Colloquium. Lyon.

Tayeb, M. 1993. English Culture and Business Organizations. In D. J. Hickson (Ed.), Management in Western Europe. Society, culture and organization in twelve nations: 47-64. Berlin/ New York: De Gruyter.

Warner, M. \& Campbell, A. 1993. German Management. In D. J. Hickson (Ed.), Management in Western Europe. Society, culture and organization in twelve nations: 89-108. Berlin/ New York: De Gruyter.

Whitley, R. (Ed.). 1992. European business systems. London: Sage.

Whitley, R. 1999. Divergent capitalisms. The social structuring and change of business systems. Oxford: Oxford University Press.

Whittington, R. \& Mayer, M. 2000. The European corporation: strategy, structure, and social science. Oxford: Oxford University Press.

Zürn, M. 1997. Was ist Denationalisierung und wieviel gibt es davon? Soziale Welt, 48: 337-360. 